\title{
Preholiday Returns and Volatility in Thai stock market
}

\author{
Nopphon Tangjitprom \\ Martin de Tours School of Management and Economics, Assumption University \\ Bangkok, Thailand
}

Tel: (66) 8-5815-6177

Email: tnopphon@gmail.com

Received: 2010-12-07

Accepted: 2011-04-28

doi:10.5296/ajfa.v2i2.525

\begin{abstract}
The purpose of this paper is to examine the holiday effect in Thailand. The holiday effect is the phenomenon in which the stock returns are abnormally high before holidays. There is no complete explanation for this phenomenon though there are many studies that state that the holiday effect has existed in the stock markets all over the world. Although there are many studies that have addressed the existence of abnormal returns during holiday periods a few studies have provided specific reasons for the existence of this phenomenon. This paper aims to study the holiday effect in returns and volatility of the Stock Exchange of Thailand. Moreover, this study examines whether the abnormal stock returns observed are associated with higher volatility during preholiday periods. Furthermore, it examines whether the holiday effect depends on the number of days in each holiday period and whether it varies between state and cultural holidays. Various GARCH models are employed to capture the volatility clustering nature of the stock market. Out of the three GARCH models considered, EGARCH $(1,1)$ model shows the best performance. The results show that preholiday returns and volatility are abnormally high. Furthermore, the longer holiday periods tend to show higher preholiday returns. However, the impact of cultural factors on abnormal returns prior to cultural holidays is not so pronounced when compared to the impact of cultural factors on abnormal returns prior to non-cultural holidays.
\end{abstract}

Keywords: Holiday, Calendar anomalies, Market Efficiency, Stock Exchange of Thailand JEL Classifications: G1, C01, G11 


\section{Introduction}

Market timing is one of the important strategies employed to make profits in stock markets. There are numerous studies addressing the situation that the daily stock returns are abnormally high for some specific days or periods during the calendar year. The existence of these abnormal returns is known as calendar anomalies or calendar effects. One of the dominant phenomena among the calendar anomalies is the situation that the stock returns are abnormally high on the trading day before the market closing day. The abnormal returns could exist both on the day before the normal weekend closing and on the day before the holidays. The abnormal returns on Friday, the trading day before the normal weekend closing, are known as weekend effect or turnof the week effect. Meanwhile, the existence of abnormal returns on the day before the holidays is known as holiday effect.

Although many studies have investigated the existence of abnormal returns during holiday periods around the world, only a few have attempted to explain why such abnormal returns exist. This paper aims to examine whether the higher returns during the preholiday periods are associated with higher volatility. The results from this study contribute to existing literature by associating the abnormally high stock returns to the higher level of volatility. Therefore, high preholiday returns are not abnormal returns but they are the rewards for risk taking by investors during preholiday period with higher volatility.

To addresses the holiday effect in the Thai stock market, the regression analysis with dummy variables technique is employed. The ordinary least squares estimator and simple $t$-test are employed to test the difference of returns between preholiday and non-preholiday periods. Furthermore, the generalized autoregressive conditional heteroskedasticity or GARCH model is applied in the analysis in order to capture the time varying volatility which is common in stock market returns. The original GARCH specification is modified by adding dummy variables in the variance equation to address the effect of preholiday periods. The asymmetric GARCH model known as the exponential GARCH or EGARCH is also utilized in order to compare the results with those from normal GARCH model. The lags of stock returns are included in the mean equation to account for possible autocorrelation. In addition, the volatility measurement from the variance equation is included in the mean equation. The combination of the above two models is referred to as the GARCH-in-Mean equation.

Some attributes of holiday periods are included in the analysis to examine the differences in preholiday returns among those different groups of attributes. The classification of holidays into cultural and state holidays is used to determine the differential effects on the preholiday returns. The number of days for each holiday period is also examined to see whether it will affect the preholiday returns differently.

\section{Literature Review}

The existence of abnormal returns in the stock market appearing before holidays is one of the market anomalies which could not be completely explained. However, the phenomenon that the stock returns are abnormally high during the trading days before the market closures has existed in stock markets as reported in many previous studies. French (1980) showed that the stock returns were consistently high on Fridays and low on Mondays. Rogalski (1984) found that the 
negative average returns on Mondays could be attributed to the average negative returns during the market closure which was measured using the closing price on Fridays and the opening price on Mondays. Roll (1983) explained that there were relatively higher returns for small-sized firms during the trading days before New Year Day. Lakonishok and Smidth (1984) also found that the stock prices tended to increase during the last trading day prior to Christmas day for anysized firms. The existence of high returns during Christmas period is referred to by them as another mystery in the stock market. Several researchers term this phenomenon as the turn-ofyear effect in which the returns are abnormally high during the turn-of-the-year and turn-of-week or weekend effect, when the returns are abnormally high during the day before weekends. If these abnormal returns occur in fact at turn-of-year, the abnormal preholiday returns should occur only during Christmas and New Year holidays. However, there were other studies that found abnormal preholiday returns during the other holidays, not only on Christmas and New Year Day. Lokonishok and Smidt (1988) showed that the preholiday returns were twenty-three times higher than average returns on the other ordinary days. They also pointed out that preholiday abnormal returns were higher than abnormal returns on Fridays. This situation is known as weekend effect. Meanwhile the returns on post-holiday days were negative, although insignificant, and were much more negative than Monday returns. Ariel (1990) showed that the returns on preholiday trading days were significantly high compared to those on the other days. His studies revealed that the average preholiday returns were around nine to fourteen times greater than the returns on non pre-holiday days. These abnormal preholiday returns are results of purchasing pressure made by investors who would like to close their short position before holidays.

Chan, Khanthavit, and Thomas (1996) studied this holiday effect by distinguishing between state holidays and cultural holidays in Malaysia, India, Singapore and Thailand. Except for Thailand, the result showed that the other three countries had significant abnormal returns during preholiday periods for cultural holidays while all four countries did not have abnormal preholiday returns for state holidays. Seiler (1993) studied the effect of market to stock returns by focusing on special closings besides the common holidays. The stock returns prior to these special closings showed above-average returns. He divided these special holidays into institutional special closings that were related to stock exchange and non-institutional special closings that were exogenous to stock exchange. The stock returns prior to institutional special closings were 30.96 times greater than the average while the stock returns prior to noninstitutional special closings were 11.04 times higher than the average.

Picou (2006) examined the holiday effect internationally by examining six major exchanges, US, Australia, Hong Kong, UK, Japan, and Canada. He found that the holiday effect still existed and there were some commonality for the holiday relation among six exchanges. This was the evidence for the holiday effect spillover, which created the opportunity to make profit.

For volatility measurement, Kiymaz and Berument (2003) employed the conditional volatility model to address the difference in volatility level among different trading days of the week. They found that the volatility was abnormally high for some specific weekdays. These week days were different in each country. For example, the highest volatility of stock returns was on Mondays for Germany and Japan but Fridays for Canada and US. 
Normally, the stock market is characterized by time varying volatility, which could be captured by conditional heteroskedasticity. The first acceptable model to explain this conditional heteroskedasticity is Autoregressive Conditional Heteroskedasticity or ARCH model proposed by Engle (1982). Bollerslev (1986) introduced the general model for ARCH as Generalized Autoregressive Conditional Heteroskedastics, or GARCH model. Akgiray (1989) showed the empirical evidence that $\operatorname{GARCH}(1,1)$, which was parsimonious, could capture the volatility of stock returns better than the other volatility models like Exponential Weighted Moving Average (EWMA) or Autoregressive Conditional Heteroskedasticity (ARCH) models.

After the introduction of capital asset pricing model or CAPM (Sharpe, 1964; Lintner, 1965; Mossin, 1966; Black, 1972) it became the dominant and most popular asset pricing model. This model is based on the basic principle that risk should be priced by rational risk-averse investors. Engle, Lilien, and Robins (1987) introduced an extension to the GARCH model by including the volatility measure from variance equation to mean equation as using the volatility to capture the risk premium as the concept that the risk should be priced by rational investors. The model was known as GARCH in mean or GARCH-M model.

Another popular extension of GARCH model was proposed by Nelson (1991) as Exponential GARCH or EGARCH. EGARCH could improve GARCH model by allowing asymmetric responses of conditional variance to the movement of return.

\section{Data and Methodology}

The daily data for SET index are gathered for the period from 1994 to 2009. Normally, Stock Exchange of Thailand implements the same holidays as announced by the central bank, Bank of Thailand. The common holidays for Thai stock market are:
a) New Year's Eve and New Year's Day
b) Makha Bucha Day
c) Chakri Day
d) Songkran Festival
e) National Labor Day
f) Coronation Day
g) Visakha Bucha Day
h) Mid Year's Closing Day
i) Asarnha Bucha Day (in the past, the holiday is Buddhist Lent Day)
j) H.M. the Queen's Birthday
k) Chulalongkorn Day
1) H.M. the King's Birthday
m) Constitution Day 
In some years there were special holidays besides the common holidays mentioned above. The stock return is computed as the log difference of daily stock prices between two consecutive trading days as follows:

$$
R_{t}=\ln \frac{P_{t}}{P_{t-1}}
$$

A test for stationarity is conducted on the stock return series to ensure the stationarity property because the non-stationary data leads to spurious regression problem. The ADF test is conducted to test the null hypothesis that the data series has unit root problem. Furthermore, the KPSS test is performed to test the null hypothesis that the data is stationary in order to confirm with the result from ADF test to ensure that the data have no unit root and are stationary.

Then the following regression equation is estimated to test the holiday effect:

$$
R_{t}=\beta_{0}+\beta_{1} D_{\text {pre }}+\varepsilon_{t}
$$

Where $R_{t}$ is the daily stock return; $D_{\text {pre }}$ is the dummy variable for pre-holiday; $\varepsilon_{\mathrm{t}}$ is a white noise error term. The interpretation of the above regression is that $\beta_{0}$ is the average returns of other days (non-preholiday). The coefficient $\beta_{1}$ will represent the difference between the preholiday and non-preholiday returns.

In order to model the volatility stock returns the $\operatorname{GARCH}(1,1), \operatorname{EGARCH}(1,1)$ and GARCH(1,1)-M models are employed. As in the model employed by Kiymaz and Berument (2003) the lag of stock returns is included in mean equation to avoid the serial correlation problems. The mean equation for both $\operatorname{GARCH}(1,1)$ and $\operatorname{EGARCH}(1,1)$ after the above modification would be:

$$
R_{t}=\beta_{0}+\beta_{1} D_{\text {pre }}+\beta_{2} R_{t-1}+\varepsilon_{t}
$$

The modified variance equation of $\operatorname{GARCH}(1,1)$ would be:

$$
h_{t}=\omega+\alpha \varepsilon_{t-1}^{2}+\beta h_{t-1}+\delta_{1} D_{p r e}
$$

The modified variance equation of $\operatorname{EGARCH}(1,1)$ would be:

$$
\log \left(h_{t}\right)=\omega+\alpha\left|\frac{\varepsilon_{t-1}}{\sqrt{h_{t-1}}}\right|+\gamma \frac{\varepsilon_{t-1}}{\sqrt{h_{t-1}}}+\beta \log \left(h_{t-1}\right)+\delta_{1} D_{t}
$$

The variance equation of $\operatorname{GARCH}(1,1)-\mathrm{M}$ is similar to $\operatorname{GARCH}(1,1)$ but the volatility measured in the variance equation is included in mean equation in the form of square root of variance. The mean equation of $\operatorname{GARCH}(1,1)-\mathrm{M}$ would be:

$$
R_{t}=\beta_{0}+\beta_{1} D_{\text {pre }}+\beta_{2} R_{t-1}+\beta_{3} \sqrt{h_{t}}+\varepsilon_{t}
$$

Moreover the assumption of Gaussian distribution for the errors may not be appropriate for GARCH model. Hence, the Generalized Error Distribution introduced by Box and Tiao (1973) has been used in research papers that employed the GARCH model. Consistent with this practice this paper also employes the GARCH model with the Generalized Error Distribution. 
Furthermore, the paper examines whether the number of days in each holiday has an effect on the preholiday returns. The regression model employed is as follows:

$$
R_{t}=\beta_{0}+\beta_{1} D_{1}+\beta_{2} D_{2}+\beta_{3} D_{3}+\varepsilon_{t}
$$

Where $R_{t}$ is the daily stock return;, $D_{l}$ is the dummy variable for pre-holiday with consisting of one- day holiday period or two- days holiday period; $D_{2}$ is the a dummy variable for pre-holiday with consisting of three- days holiday period; $D_{3}$ is the dummy variable for pre-holiday before holiday periodconsisting of more than three days. For volatility measurement equation 6 is modified by adding the lagged stock returns and this equation is known as mean equation in both GARCH and EGARCH models. For GARCH-M model the standard deviation measured by square root of conditional variance is added to mean equation. The variance equation would follow equations 4 and 5 but replace the dummy variables with dummy variables from equation 7.

Finally, the distinction whether state holidays and/or cultural holidays can affect the preholiday returns is examined. Cultural holidays based on the definition by Chan, Khanthavit, and Thomas (1996) are Songkran days and Buddhist holidays like Macha Bucha, Visakha Bucha, Asarnha Bucha, and the Buddhist Lent day. Other holidays are classified as state holidays. The regression equation estimated is as follows:

$$
R_{t}=\beta_{0}+\beta_{1} D_{\text {state }}+\beta_{2} D_{\text {culture }}+R_{t-1}+\varepsilon_{t}
$$

Where $R_{t}$ is the daily stock returns; $D_{l}$ is the dummy variable of preholiday for cultural holidays; $D_{2}$ is the dummy variable for preholiday for state holidays. For volatility measurement, the dummy variables in mean equation and variance equation would be replaced by dummy variables from equation 8 .

\section{Analysis and Result}

Table 1 reports frequencies for for holidays consisting of one to five days. From the Stock Exchange of Thailand during 1992 to 2009 the total number of trading days was 3,923 days. During this period, there were 206 holidays which could be classified into 142 state holidays and 64 cultural holidays. 


\begin{tabular}{cc} 
Table 1. Frequencies for holidays classified \\
according to the number of days in each \\
holiday period \\
\hline $\begin{array}{c}\text { Number of days } \\
\text { in the holiday } \\
\text { period }\end{array}$ & Frequency \\
\hline 1 & 75 \\
2 & 1 \\
3 & 100 \\
4 & 24 \\
5 & 6
\end{tabular}

Table 2 reports the descriptive statistics and the result of unit root tests on SET returns. As the table the average of the daily stock returns during the study period is $-0.0207 \%$. The stock returns series shows high excess kurtosis or is leptokurtic. This indicates volatility persistence and should be modeled by conditional heteroskedasticity models like GARCH. For the ADF tests, the null hypothesis of a unit root could be rejected meaning that there is no unit root in the daily stock return series. The stationary of series is confirmed by KPSS test also as the null hypothesis of stationary could not be rejected. Therefore, the stock series is stationary and could be used in further analysis without any transformation. 
Table 2. Descriptive statistics and unit root test results for SET Return

\begin{tabular}{lccc}
\hline \multicolumn{1}{c}{ Descriptive Statistics } & Unit Root and Stationary Test \\
\hline Mean & -0.000207 & ADF test & \\
Median & -0.000367 & No intercept and trend & $-56.6632^{* *}$ \\
Maximum & 0.113495 & With intercept only & $-56.6632^{* *}$ \\
Minimum & -0.160633 & With intercept and trend & $-56.7063^{* *}$ \\
Std. Dev. & 0.017468 & KPSS test & \\
Skewness & 0.064731 & With intercept & 0.3852 \\
Kurtosis & 9.223285 & With intercept and trend & 0.0827 \\
\hline
\end{tabular}

**Significant at $5 \% \quad *$ Significant at 10\%

Table 3 reports the result of various models capturing preholiday returns and volatility. The constant of $O L S$ regression equation shows that the returns of non-preholidays are negative at 0.0412 . The coefficient of the dummy variable representing the difference in average returns between preholiday and other days is $0.3910 \%$ reflecting that the preholiday returns are significantly higher than non-preholiday returns. The $O L S$ regression suffers from the conditional heteroskedasticity as per the ARCH-LM test. Conditional heteroskedasticity models such as $\operatorname{GARCH}(1,1)$ or EGARCH $(1,1)$ would be more attractive than normal OLS regression as they capture volatility in stock returns. The results of both GARCH model and EGARCH model are consistent as both can eliminate the conditional heteroskedasticity and the preholiday still shows higher returns than non-preholiday. However, the GARCH-M model cannot eliminate the conditional heteroskedasticity and therefore GARCH-M model is not appropriate to be used in further analysis. The coefficient of asymmetric term $(\gamma)$ of EGARCH model is -0.049 which is significant at the five per cent level. The value of as the Akaike Information Criteria (AIC) and Schwarz Bayesian Information Criteria (SIC) for GARCH model is -5.5541 and -5.5492, respectively. The AIC and SIC for EGARCH model are -5.5645 and -5.5501 , respectively. This means that the performance of the EGARCH model is better than that of the GARCH model. The coefficient of dummy variable representing preholiday in variance equation from both GARCH and EGARCH models is positive meaning that the volatility would be higher during the preholiday period. Therefore, the higher returns during preholiday periods come with higher volatility. 
Table 3. Test of preholiday returns and volatility

\begin{tabular}{lllll}
\hline Variable & OLS & GARCH$(1,1)$ & EGARCH $(1,1)$ & GARCH(1,1)-M \\
\hline Mean Equation & & & & \\
Constant & -0.000412 & -0.000138 & 0.000250 & -0.002204 \\
$\mathrm{D}_{\text {pre }}$ & $0.003910^{* *}$ & $0.003237^{* *}$ & $0.003266^{* *}$ & $0.003657^{* *}$ \\
$\mathrm{R}_{\mathrm{t}-1}$ & & $0.081487^{* *}$ & $0.078491^{* *}$ & $0.114905^{* *}$ \\
$\sqrt{h}$ & & & & 0.154426 \\
\hline Variance Equation & & & & \\
constant & & 0.000006 & -0.482098 & 0.000189 \\
$\alpha$ & & $0.115105^{* *}$ & $0.219027^{* *}$ & $0.109967^{* *}$ \\
$\beta$ & & $0.861138^{* *}$ & $0.963238^{* *}$ & $0.500793^{* *}$ \\
$\gamma$ & & & $-0.049052^{* *}$ & \\
$\mathrm{D}_{\mathrm{pre}}$ & & $0.000032^{* *}$ & $0.178332^{* *}$ & $-0.000253^{* *}$ \\
\hline ARCH(5) & $418.7093^{* *}$ & 1.3118 & 0.8364 & $54.1836^{* *}$ \\
ARCH(10) & $478.0745^{* *}$ & 2.1861 & 1.1906 & $83.3482^{* *}$ \\
\hline AIC & -5.2585 & -5.5541 & -5.5645 & -5.4949 \\
SIC & -5.2553 & -5.5492 & -5.5501 & -5.4821 \\
\hline
\end{tabular}

**Significant at $5 \% *$ Significant at $10 \%$

After confirming that abnormal returns on preholidays have existed in Thai stock market, further investigation is carried out to see whether the number of days during holiday periods can affect the level of preholiday returns. Table 4 reports the results of various models capturing the preholiday returns and volatility based on the number of days in each holiday period. From $O L S$ regression, the coefficient of dummy variable representing the difference in average returns between preholiday consisting of one-and-two-days is $0.25 \%$ while the preholiday returns for three-day holiday period is $0.3817 \%$ and the preholiday returns for more than three days is $0.7792 \%$. This means that the longer the holiday period the higher will be the level of preholiday abnormal returns, though only the preholiday returns for holidays consisting of more than two days has shown significant differences from those for non-preholidays. All GARCH models show that they can be used to capture conditional heteroskedasticity. The significance of the asymmetric term of the and the lower value of AIC and SIC shows that EGARCH model is better than GARCH and GARCH-M models. The GARCH models where the volatility of the longest holiday periods is considered perform better than the other GARCH models. Therefore, the long holiday period will lead to higher abnormal preholiday returns that come with higher volatility. 
Table 4. Preholiday returns and volatility based on number of days for each holiday period

\begin{tabular}{lllll}
\hline Variable & OLS & GARCH$(1,1)$ & EGARCH(1,1) & GARCH(1,1)-M \\
\hline Mean Equation & & & & \\
Constant & -0.000412 & -0.000143 & -0.000249 & 0.000624 \\
$\mathrm{D}_{1}$ & 0.002500 & 0.002203 & $0.002800^{*}$ & 0.002288 \\
$\mathrm{D}_{2}$ & $0.003817^{* *}$ & $0.002732^{* *}$ & $0.002975^{* *}$ & $0.002793^{* *}$ \\
$\mathrm{D}_{3}$ & $0.007792^{* *}$ & $0.005554^{*}$ & $0.005586^{*}$ & $0.005702^{* *}$ \\
$\mathrm{R}_{\mathrm{t}-1}$ & & $0.080028^{* *}$ & $0.078609^{* *}$ & $0.081888^{* *}$ \\
$\sqrt{h}$ & & & & -0.056210 \\
\hline Variance Equation & & & & \\
constant & & 0.000006 & -0.503737 & 0.000006 \\
$\alpha$ & & $0.115602^{* *}$ & $0.222532^{* *}$ & $0.117237^{* *}$ \\
$\beta$ & & $0.859258^{* *}$ & $0.960941^{* *}$ & $0.858281^{* *}$ \\
$\gamma$ & & & $-0.051984^{* *}$ & \\
$\mathrm{D}_{1}$ & & 0.000038 & $0.178525^{*}$ & 0.000035 \\
$\mathrm{D}_{2}$ & & 0.000021 & 0.090299 & 0.000021 \\
$\mathrm{D}_{3}$ & & $0.000064^{*}$ & $0.434052^{* *}$ & $0.000068^{*}$ \\
\hline $\mathrm{ARCH}(5)$ & $417.6787^{* *}$ & 1.0804 & 0.6376 & 1.1032 \\
$\mathrm{ARCH}(10)$ & $476.8141^{* *}$ & 1.8906 & 0.9744 & 1.9377 \\
\hline $\mathrm{AIC}$ & -5.2581 & -5.5587 & -5.5638 & -5.5577 \\
$\mathrm{SIC}$ & -5.2516 & -5.5395 & -5.5430 & -5.5369 \\
\hline & & & & \\
\hline
\end{tabular}

**Significant at $5 \% \quad *$ Significant at $10 \%$

Finally, the preholiday returns are further examined to see whether they are related to the holiday type, cultural holidays and state holidays. Table 5 reports the results of various models capturing the preholiday returns and volatility with the distinction between state holidays and cultural holidays. The result based on the $O L S$ regression shows that the returns on state holidays are statistically significantly higher than non-preholiday returns by $0.4186 \%$. The returns on cultural holidays are only $0.3299 \%$ higher than non-preholiday returns. However, this difference is not statistically significant. Based on Wald's coefficient test the returns on state holidays and cultural holidays are not statistically different. The results from all GARCH models show similar results that they can capture the conditional volatility. The returns are abnormally high only for state holidays but not for cultural holidays, and only state holidays show a positive effect on the 
volatility level. This finding contradicts those of previous research that show abnormal preholiday returns come with cultural preholidays and not with state preholidays.

Table 5. Preholiday returns and volatility for state holidays and cultural holidays

\begin{tabular}{|c|c|c|c|c|}
\hline Variable & OLS & $\operatorname{GARCH}(1,1)$ & EGARCH( 1,1$)$ & GARCH(1,1)-M \\
\hline \multicolumn{5}{|c|}{ Mean Equation } \\
\hline Constant & -0.000412 & -0.000141 & -0.000263 & 0.000630 \\
\hline State $^{1}$ & $0.004186^{* *}$ & $0.003518 * *$ & $0.003736^{* *}$ & $0.003550 * *$ \\
\hline Cultural $^{1}$ & 0.003299 & 0.002131 & 0.001742 & 0.002186 \\
\hline $\mathrm{R}_{\mathrm{t}-1}$ & & $0.081207 * *$ & $0.078469 * *$ & $0.082863 * *$ \\
\hline$\sqrt{h}$ & & & & -0.056679 \\
\hline \multicolumn{5}{|c|}{ Variance Equation } \\
\hline constant & & 0.000006 & -0.463816 & 0.000005 \\
\hline$\alpha$ & & $0.114073 * *$ & $0.214481 * *$ & $0.115450 * *$ \\
\hline$\beta$ & & $0.862990 * *$ & $0.964987 * *$ & $0.862323 * *$ \\
\hline$\gamma$ & & & $-0.049170 * *$ & \\
\hline State & & $0.000037 * *$ & $0.225726 * *$ & $0.000036 * *$ \\
\hline Cultural & & 0.000018 & 0.052922 & 0.000020 \\
\hline $\mathrm{ARCH}(5)$ & $418.7093 * *$ & 1.2399 & 0.9577 & 1.2695 \\
\hline $\mathrm{ARCH}(10)$ & $478.0745 * *$ & 2.1526 & 1.3487 & 2.2117 \\
\hline $\mathrm{AIC}$ & -5.2581 & -5.5591 & -5.5641 & -5.5579 \\
\hline SIC & -5.2532 & -5.5431 & -5.5465 & -5.5403 \\
\hline
\end{tabular}

**Significant at $5 \% \quad *$ Significant at $10 \%$

${ }^{I}$ The test statistics of Wald's F test between coefficient of state holiday dummy and cultural holiday dummy is 0.113870 , which is not significant at 10\%.

During the sample period of this study, the stock market performance in Thailand may have been affected by the Asian Crisis in 1997. In order to control for this event a dummy variable representing the period of Asian Crisis in Thailand is introduced into the model. The period of Asian Crisis in Thailand is the period between 1996 and 1998. This dummy variable would be added to both mean and variance equations to control the effect on both mean and volatility levels. Table 6 reports the results of the EGARCH model after controlling for the Asian Crisis. The negative coefficient of the dummy variable for Asian Crisis in the mean equation shows that the returns are abnormally low during the crisis period. Moreover, the positive coefficient of the dummy variable for Asian crisis in the variance equation shows that the level of volatility is 
higher during the crisis period. The other coefficients show qualitatively similar results obtained from the models estimated earlier. This implies that the effect of the Asian crisis does not alter the abnormal returns and higher volatility during the preholiday periods. Furthermore, it does not alter the results related to the number of holidays and state holidays and cultural holidays reported earlier.

Table 6. The EGARCH result after controlling for the Asian Crisis in 1996-1998

\begin{tabular}{|c|c|c|c|}
\hline Variable & Model 1 & Model 2 & Model 3 \\
\hline \multicolumn{4}{|c|}{ Mean Equation } \\
\hline Constant & 0.000108 & 0.000102 & 0.000099 \\
\hline $\mathrm{D}_{\text {pre }}$ & $0.003405^{* *}$ & & \\
\hline $\mathrm{D}_{1}$ & & 0.002470 & \\
\hline $\mathrm{D}_{2}$ & & $0.003313^{* *}$ & \\
\hline $\mathrm{D}_{3}$ & & $0.005935^{* *}$ & \\
\hline State & & & $0.003641^{* *}$ \\
\hline Cultural & & & 0.001884 \\
\hline $\mathrm{R}_{\mathrm{t}-1}$ & $0.076572 * *$ & $0.076072 * *$ & $0.075986^{* *}$ \\
\hline $\mathrm{D}_{1996-1998}$ & $-0.003210^{* *}$ & $-0.003227 * *$ & $-0.003227 * *$ \\
\hline \multicolumn{4}{|c|}{ Variance Equation } \\
\hline constant & -0.548994 & -0.580894 & -0.528907 \\
\hline$\alpha$ & $0.225075^{* *}$ & $0.229726^{* *}$ & $0.220699 * *$ \\
\hline$\beta$ & $0.956492 * *$ & $0.953094 * *$ & $0.958448 * *$ \\
\hline$\gamma$ & $-0.052011 * *$ & $-0.055949 * *$ & $-0.052137 * *$ \\
\hline $\mathrm{D}_{\text {pre }}$ & $0.174998 * *$ & & \\
\hline $\mathrm{D}_{1}$ & & 0.169166 & \\
\hline $\mathrm{D}_{2}$ & & 0.086976 & \\
\hline $\mathrm{D}_{3}$ & & $0.451380 * *$ & \\
\hline State & & & $0.219654 * *$ \\
\hline Cultural & & & 0.060436 \\
\hline $\mathrm{D}_{1996-1998}$ & $0.032669^{* *}$ & $0.034581 * *$ & $0.031467 * *$ \\
\hline
\end{tabular}

**Significant at $5 \% \quad *$ Significant at $10 \%$ 


\section{Conclusion}

This research investigated the holiday effect in the Thai stock market. The overall market performance is examined from SET index, which is the market value-weighted index of all stocks traded in the Stock Exchange of Thailand. The result confirms that the holiday effect exists in Thailand because the stock returns are abnormally high during the preholiday trading day. Even after the model is adjusted to account for conditional heteroskedasticity by various GARCH models, the result is still the same in which the returns for preholiday periods are statistically higher than non-preholiday periods. However, there is an interesting issue that the preholiday period with abnormally above-average returns comes with higher volatility level. The higher volatility may arise from the fact that most holidays in Thailand are not the same as those in the other countries. There is only the New Year holiday which is a holiday for all countries including Thailand. This may create uncertainty in investors as it is unpredictable as to what will happen to global markets during the market closure on Thai holidays.

Furthermore, the preholiday returns are higher for the long holiday periods. Only the preholiday with more than two days show statistically significantly higher returns compared to those during non-preholiday periods while the preholiday periods with one to two days show higher returns that are not statistically significant. After distinguishing between state and cultural holidays, only state holidays show statistically significantly higher returns compared to those during nonpreholiday periods while the returns during cultural holidays are not statistically significantly higher. However, there is no statistical difference between preholiday returns between state and cultural holidays. Further, the Asian Crisis has similar effects on returns during preholiday and cultural holiday periods. However. there are abnormal returns and higher volatility during preholiday periods.

The abnormal preholiday returns exist in Thailand, especially for state holidays and holidays with more than two days. However, the magnitude of these abnormal preholiday returns is too small to take advantage of for making profits because the transaction costs of $0.83 \%$ coming from the minimum standard roundtrip commission fees in Thai stock market at $0.3 \%$ and the average bid-ask spread computed from the tick size at around $0.53 \%$. Moreover, investing during preholiday comes with higher volatility, implying higher risks. Therefore, it is questionable that the preholiday returns are really profitable rational risk-averse investors.

Even though it is difficult to exploit these preholiday returns, the evidence of the existence of preholiday abnormal returns could give a clue to investors on the timing of investments. Furthermore, the higher preholiday volatility reflects investors' behavior during market closure on Thai holidays, which can create abnormal buying and selling activities during preholiday trading days.

\section{References}

Akgiray, V. (1989). Conditional Heteroscedasticity in Time Series of Stock Returns: Evidence and Forecasts. The Journal of Business, 62, 55-80.

Ariel, R. A. (1990). High Stock Returns before Holidays: Existence and Evidence on Possible Causes. The Journal of Finance, 45, 1611-1626. 
Black, F. (1972). Capital Market Equilibrium with Restricted Borrowing. Journal of Business, 45, 444-454.

Bollerslev, T. (1986). Generalized Autoregressive Conditional Heteroskedasticity. Journal of Econometrics, 31, 307-327.

Box, G. E., \& Tiao, G. C. (1973). Bayesian Inference in Statistical Analysis. Reading, MA: Addison-Wesley Publishing Co.

Chan, M. W. L., Khanthavit, A., \& Thomas, H. (1996). Seasonality and cultural influences on four Asian stock markets. Asia Pacific Journal of Management, 13, 1-24.

Engle, R. (1982). Autoregressive Conditional Heteroskedasticity with Estimates of the Variance of U.K. Inflation. Econometrica, 50, 987-1008.

Engle, R. F., Lilien, D. M., \& Robins, R. P. (1987). Estimating Time Varying Risk Premia in the Term Structure: The Arch-M Model. Econometrica, 55, 391-407.

French, K. (1980). Stock returns and the weekend effect. Journal of Financial Economics, 8(1), 55-69.

Kiymaz, H., \& Berument, H. (2003). The day of the week effect on stock market volatility and volume: International evidence Review of Financial Economics, 12, 363-380.

Lakonishok, J., \& Smidt, S. (1984). Volume and turn-of-the-year behavior. Journal of Financial Economics, 13, 435-456.

Lakonishok, J., \& Smidt, S. (1988). Are seasonal anomalies real? A ninety-year perspective. Review of Financial Studies, 1, 403-425.

Lintner, J. (1965). The Valuation of Risk Assets and the Selection of Risky Investments in Stock Portfolios and Capital Budgets. Review of Economics and Statistics, 47, 13-37.

Mossin, J. (1986). Equilibrium in a Capital Asset Market. Econometrica, 34(4), 768-783.

Nelson, D. B. (1991). Conditional Heteroskedasticity in Asset Returns: A New Approach. Econometrica, 59, 347-370.

Picou, A. (2006). Stock returns behavior during holiday periods: evidence from six countries. Managerial Finance, 32, 433-445.

Rogalski, R. J. (1984). New Findings Regarding Day-of-the-Week Returns over Trading and ... The Journal of Finance, 39, 1603-1614.

Roll, R. (1983). Vas ist das? Journal of Portfolio Management, 9, 18-28.

Seiler, M. J. (1993). Historical pre and post special closing effects. Studies in Economics and Finance, 18, 59-73.

Sharpe, W. F. (1964). Capital Asset Prices: A Theory of Market Equilibrium under Conditions of Risk. Journal of Finance, 19, 425-442. 